\title{
Research on Ideological Concepts of People in Song Dynasty from the Perspective of Folk Songs and Proverbs
}

\author{
Dongxia Song \\ Yancheng Teachers University, Yancheng, Jiangsu, 224007
}

Keywords: Song Dynasty; folk songs and proverbs; people’s ideological concepts

\begin{abstract}
Folk songs and proverbs is a typical folk culture, but its creation, recording, and communication are inseparable from the participation of literati. From the analysis of folk songs and proverbs recorded in Song Dynasty, the literati in Song Dynasty not only recorded the oral rumors, but also kept them in inscriptions and various books, enhancing the communication effect, and the creation and dissemination of folk songs and proverbs, which plays a role in fueling the waves. On the basis of investigating the spread of folk songs and proverbs in Song Dynasty, revealing the role of literati in Song Dynasty helps to further explore the position and influence of literati in the inheritance of folk culture.
\end{abstract}

\section{Introduction}

Hey, often referred to as folk songs, is a typical folk culture. The spread and acceptance of Folk songs and proverbs is generally defined as "the people" in general terms, usually distinguished from the elite culture of the literati. If we divide the creation, dissemination, and acceptance groups of Folk songs and proverbs from a cultural perspective, they can be roughly divided into two levels: literati level and folk level. At the literati level, there are differences between the upper-level scholar-officials and the middle-lower literati; the situation at the folk level is more complicated, such as self-cultivating farmers, tenant farmers, emerging citizens, and craftsmen, businessmen, and people of all walks of life. But this division is not absolute. The various classes are not isolated, but in a dynamic mobile system that is mutually dependent, and the "people" themselves include some non-official literati. When discussing the phenomenon of communication and acceptance, this the definition is only relative, but it is of great significance for the discussion of socialization from the perspective of social groups. Similarly, it is of great significance to reveal the special status and influence of literati in cultural creation and inheritance. The role of literati is not only applicable to elite culture, but also to folk culture. This thesis attempts to reveal the phenomenon of the spread of literati in the Song Dynasty through the discussion of the way of communication in the Song Dynasty, and reveals the important role of the literati who are easily overlooked but actually exist in the creation and dissemination of folk culture.

\section{Loyalty and Filial Concept}

China's form of state organization has the characteristics of home state isomorphism, with strong family ethics, patriarchal color and color. "Mencius - On the shackles" said that "people have constant words, they all blame "the world under the country." The world is in the country, the country is at home ...." The country is the enlargement of the home, the home is the epitome of the country. At home, the paternal patriarch is in charge of the country, and the monarch is everything. The monarch controls the whole society by controlling one parent, while the parents control the most basic social units of the country through the control of family members. The monarch is the national leader. Mr. Tian Jiaying pointed out that "this strict patriarchal system, the inheritance method of the status of parents, and the various clan relations that arise with these are called the patriarchal system." In the home of the country, as long as the authority of the monarch and the parents is maintained, the country and the country The family can be maintained and the society will be stable. If the two lose control of other parents and members, the society will be turbulent or 
even collapse. For the monarch, the most influential parents are undoubtedly the ministers of the court. For parents, the family's instability is the other members of the family. This is one of the main reasons why the ancient Chinese society has always praised the loyal ministers and filial piety. In the early Han Dynasty, the "Xiao Jing" said that at the core of ethical concepts, loyalty is an extension of filial piety. In view of the status of loyalty and filial piety in the hearts of Chinese people, Chinese Buddhists have been striving to incorporate Chinese traditional ethical concepts into Buddhist theories in order to adapt to the situation and thus establish a stable foothold in China. Unlike Indian Buddhism, which considers children and parents to be equal and equal, Chinese Buddhism believes that parents and children are a strict hierarchical distinction. In the Song Dynasty, loyalty and filial piety was increasingly absorbed by Buddhist ideas. In essence, this is the strong assimilation of Chinese culture. The process of Buddhism's introduction to China is also the process of its assimilation of Chinese culture. The "School of Filial Piety" in the Northern Song Dynasty is an important work systematically expounding the integration of filial piety and Buddhism. He proposed "Fu Xiao, Tian Jing, the righteousness of the land, and the people's trip", from the height of the fundamental law of heaven and earth to demonstrate the reciprocity of parents. Filial piety concept. The illusory hall of the Southern Song Dynasty regards filial piety as the foundation of the universe. "The world is big, filial piety is based", "based on filial piety, it feels the world, and moves ghosts and gods." The change of the intellectual class thoughts finally penetrated into the grassroots society and the public. The outstanding performance is that Buddhism's concept of "the head of good and evil" began to shift from the problem of killing to the issue of loyalty and filial piety.

\section{Greed Ideas}

The Song Dynasty was a peak in China's ancient economic development. Although the traditional "heavy agriculture and trade suppression" policy is still being implemented, the objective laws of economic development are unstoppable. The events that we are familiar with, such as the combination of the city and the city, the hook-and-barn corrugated, and the circulation of paper money, which reflect the development level of the commodity economy, all appeared in the Song Dynasty. With the development of the commodity economy, people are paying more and more attention to the wealth of currencies and commodities other than land and grain. However, although the gentleman loves money, he must have a way to do it. The people who gather money by treacherous means have never been false since ancient times. It is inevitable that evil reports will naturally occur. On the contrary, if you do not take the unjust money, you will often get the favor of heaven. With the development of the commodity economy in the Song Dynasty, people paid more and more attention to the wealth of money, and the number of people who used their means to seek money increased, and the interests of the people were damaged. So people must find ways to punish evil and promote good. In the case of the prevalence of retribution, it is natural to give retribution in different ways to those who are greedy for money and who are not greedy or not.

The relationship between Folk songs and proverbs and literati is not the same. From another perspective, the people naturally have to be influenced by the mainstream consciousness and mainstream culture, and are influenced by the ideology of the literati. For the people, the most typical influence is the smoke of the mainstream consciousness culture centered on Confucianism. In terms of thought and action, it becomes a potential spiritual standard. This influence will inevitably penetrate into their oral creations. In addition, it is worth noting that the public's sentiments are mostly derived from the practical experience of production and life, while the practical experience is often more emotional than rational, and if it is separated from a specific environment, it may even become a one-sided knowledge. In the folk songs, it is inevitable that there is a one-sided practical experience. The overcoming of this shortcoming, the participation of the literati is obviously necessary. After careful elaboration and transformation of the literati to make it more perfect and then give it to the people's society, this is an idealized concept, but it is indeed a reality in the process of communication and re-creation. A bamboo branch writer once pointed out: "The husband and wife are aspiring, and there are many things to take.... Or in the 
sacredness of the land, or in the world, there is no load, and the essays are the legacy of the township party. The scholars are collecting and losing. The narration of the lyrics, the collection of this and the people of the lower Libba." 3 The oral folk songs scattered in all corners of society in history have been transformed into words to be preserved, and then "to the lower Liba people", can not but be said to be literati The credit. In the literati's recording activities, it is almost certain that the folk songs will inevitably pass their retouching and processing. Although the literati's interest has a clear distance from the public, the lively and vivid folk songs really touched them. The intellectual class often consciously imitates or uses poetry to write poetry and narration, and also makes folk elements manifest in orthodox literary works. At the same time, literati also use this form to spread their ideas and consciousness to the lower classes. In addition, many confusing beggars can neither be too deep nor too straightforward. It takes a little thought to make up, obviously not from the hands of ordinary people like soldiers and pawns, but only in the literati. On account. From this point of view, the so-called "achievement" and "codification", the right to invent should be attributed to the literati.

\section{People's Participation in Folk Songs and Proverbs and Sense of Urgency}

Mo Yan Wang Dao is far away, and listens to the people's words. The folk songs are like the voices of the people's attention to real politics. They carry real worries and social perceptions. Although they are not comprehensive, just as Sima Qian said: “Talk about it, Can also solve the problem. "It is also said that "there is no stagnation in the upper and lower, and people are harmed by the use of the Tao." The form of speech that is marked by the public opinion is superior to the monarch, and is not guilty of the monarch. Even if it is not properly, it cannot constitute an individual. Threat. It is both righteous and dismissal. I have to admit that Folk songs and proverbs is an art, a clever and simultaneous political statement, which invisibly enhances the social function and value of the shackles. There are many different ways, a variety of colors, a straightforward flaw, a clever irony, a ridicule of organic intelligence, a witty banter, and a ruthless flogging. These orientations seem to cover all, and are more concise, The refined form is presented. The public's comments on the government's policy are fair and easy, and the comments on the officials' merits and demerits are often reflected by the folk songs, forming a civil society paradox. Observing the political situation, the situation is different, some with A clearer political direction (such as a rumor deliberately created by a sinister political opponent), but most of them are purposeless, and more are the expression of public opinion. Broadcasting and accepting can also play a role in the government's policy implementation and supervision of the officials' virtues. It is precisely because of the close integration of the shackles and the real society that they often become an important expression of the "public opinion" in the political arena. At the beginning, it was given the care of reality, reflecting the state of the majority of the people participating in real politics in a unique way, reflecting the public participation and awareness of the people.

\section{Conclusion}

With the help of the shackles, the people play a historical role in a unique way, convey the sense of social history in the casual shackles, and contain profound wisdom. Their witty life attitudes are clearly visible, and at the same time they play the role of cultivating the people in communication. . More importantly, through the embarrassment of a particular era, we can clearly observe the sense of urgency that the people are deeply concerned with and the process by which they participate in social history in a unique way. The contents of folk songs are also true and false, and they are also true. The records kept in the literature have many objective facts and also include irrational expressions. However, in any case, people of all ages are creating, spreading, and constantly Communicate the concept of the people of a particular era. For social history, the authenticity is important, but people's ideas and concepts conveyed by generations have obviously become one of the important significance of their research. Moreover, many of the shackles of people's love, social perception, and character evaluation in a particular era have become historical illusions with the 
passage of time. Because some of the remains of various documents accidentally do not hinder us from history. The discussion of the people's ideological concepts contained in the shackles, in a sense, this kind of accidentally makes it retain the natural side, born with a historical truth. The discussion of the concept of the people in the imperial connotation has made the social history value of ancient Chinese monks powerfully manifested.

\section{References}

[1] Yu Caizhong. Public opinion and judicial justice--the characteristics of judicial public opinion in the network environment and its response [J]. Legal System and Society, 2011 (12).

[2] Chen Zhiyu. A review of the cultural history of the Northern Song Dynasty [J]. Beijing: China Social Sciences Press, 1992.

[3] Lang Guohua. News control in the Song Dynasty [J]. Journal of South China Normal University, 2000 (2).

[4] Zhao Yaodan. On the social connotation of the Suizhong in the Song Dynasty [J]. Dongyue Forum, 2013 (5). 